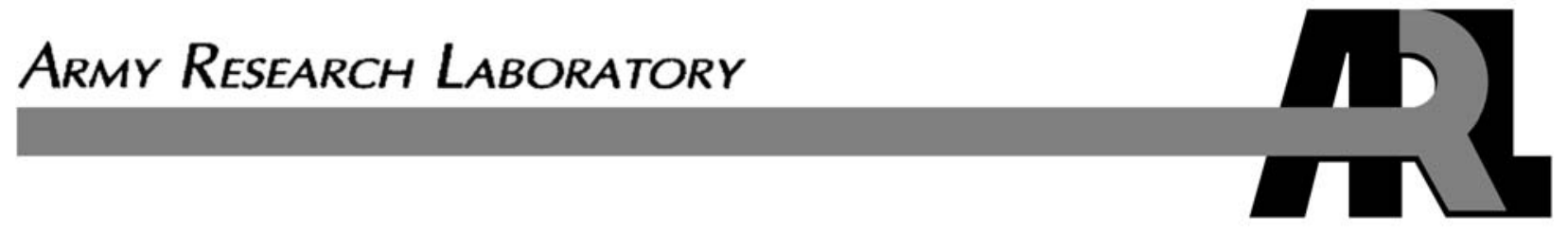

\title{
Procedures for Using the AMANDA Model in Acceleration Response Studies (Tutorial by Example)
}

\author{
by Owen P. Litt
}

ARL-TR-3333

September 2004 


\section{NOTICES}

\section{Disclaimers}

The findings in this report are not to be construed as an official Department of the Army position unless so designated by other authorized documents.

Citation of manufacturer's or trade names does not constitute an official endorsement or approval of the use thereof.

Destroy this report when it is no longer needed. Do not return it to the originator. 


\title{
Army Research Laboratory
}

Aberdeen Proving Ground, MD 21005-5068

ARL-TR-3333

September 2004

\section{Procedures for Using the AMANDA Model in Acceleration Response Studies (Tutorial by Example)}

\author{
Owen P. Litt
}

Survivability/Lethality Analysis Directorate, ARL 
Public reporting burden for this collection of information is estimated to average 1 hour per response, including the time for reviewing instructions, searching existing data sources, gathering and maintaining the data needed, and completing and reviewing the collection information. Send comments regarding this burden estimate or any other aspect of this collection of information, including suggestions for reducing the burden, to Department of Defense, Washington Headquarters Services, Directorate for Information Operations and Reports (0704-0188),

1215 Jefferson Davis Highway, Suite 1204, Arlington, VA 22202-4302. Respondents should be aware that notwithstanding any other provision of law, no person shall be subject to any penalty for failing to comply with a collection of information if it does not display a currently valid OMB control number.

PLEASE DO NOT RETURN YOUR FORM TO THE ABOVE ADDRESS.

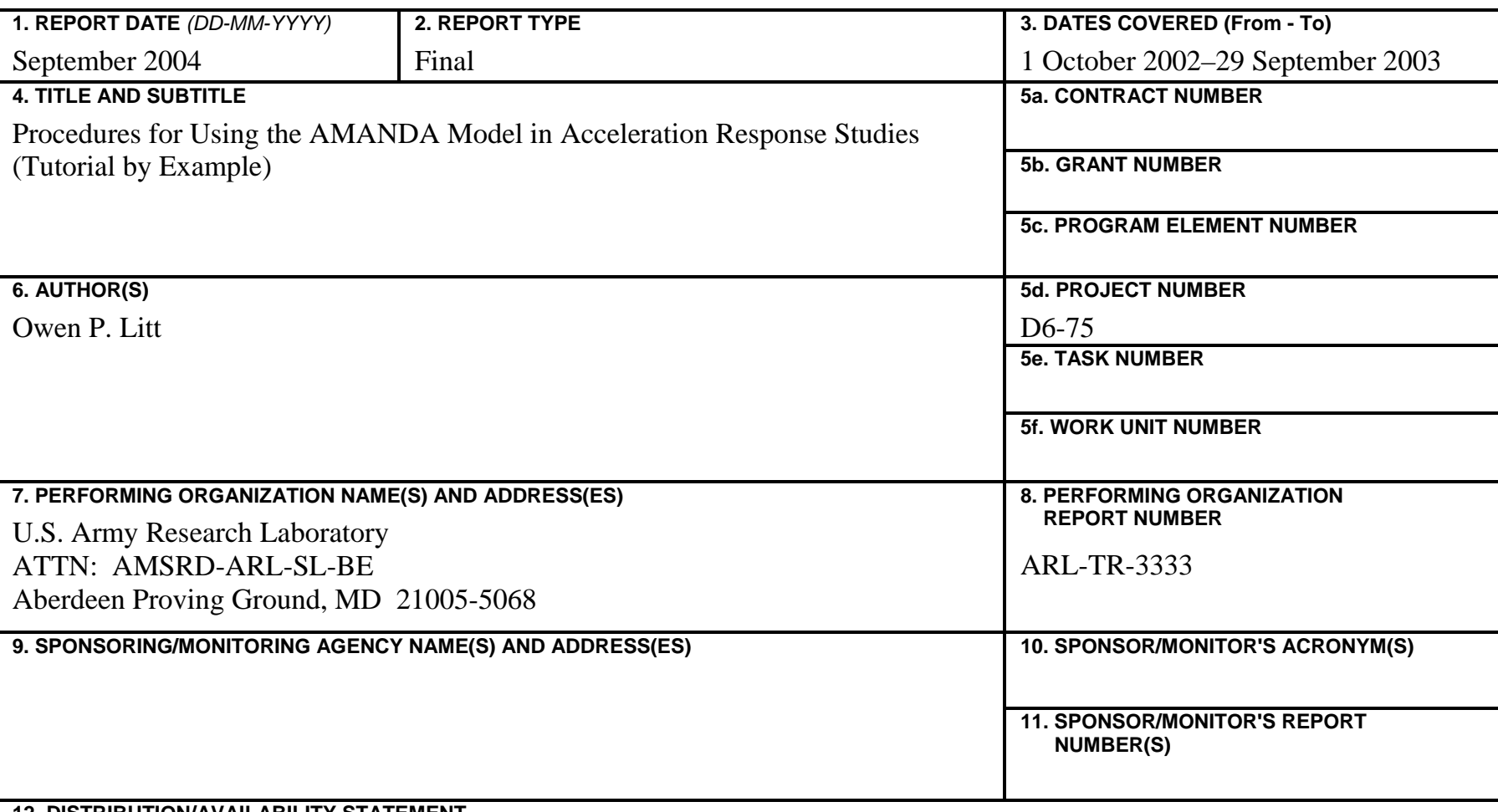

12. DISTRIBUTION/AVAILABILITY STATEMENT

13. SUPPLEMENTARY NOTES

Approved for public release; distribution is unlimited.

14. ABSTRACT

This report describes the procedures for using the AMANDA model in acceleration response studies. It includes processing of acceleration time-history data for inputting the data into AMANDA and applying AMANDA, which predicts head, chest, and pelvis acceleration, in order to predict injury. The ORCA modeling system is a computer software package that provides a comprehensive standardized casualty assessment methodology associated with weapon-induced injuries. It also includes recommended improvements to enhance Amanda model capabilities within the ORCA modeling system. Sets of acceleration time-history data from a live-fire test are included as an example in order to enhance the clarity of the described procedure.

\section{SUBJECT TERMS}

ORCA, AMANDA, acceleration, injury analysis, accelerometer, head, chest, pelvis, data file, legend-file, elemental capability vectors

\begin{tabular}{|c|c|c|c|c|c|}
\hline \multicolumn{3}{|c|}{ 16. SECURITY CLASSIFICATION OF: } & \multirow[t]{2}{*}{$\begin{array}{l}\text { 17. LIMITATION } \\
\text { OF ABSTRACT }\end{array}$} & \multirow{2}{*}{$\begin{array}{l}\text { 18. NUMBER } \\
\text { OF PAGES } \\
22\end{array}$} & \multirow{2}{*}{$\begin{array}{l}\text { 19a. NAME OF RESPONSIBLE PERSON } \\
\text { Owen P. Litt } \\
\text { 19b. TELEPHONE NUMBER (Include area code) }\end{array}$} \\
\hline $\begin{array}{l}\text { a. REPORT } \\
\text { UNCLASSIFIED }\end{array}$ & $\begin{array}{l}\text { b. ABSTRACT } \\
\text { UNCLASSIFIED }\end{array}$ & $\begin{array}{l}\text { c. THIS PAGE } \\
\text { UNCLASSIFIED }\end{array}$ & & & \\
\hline
\end{tabular}




\section{Contents}

List of Figures $\quad$ iv

List of Tables $\quad$ iv

$\begin{array}{ll}\text { Acknowledgments } & \text { v }\end{array}$

$\begin{array}{ll}\text { 1. Introduction } & 1\end{array}$

2. Analysis 1

3. Summary of Results $\quad 1$

4. Method of Analysis $\quad 2$

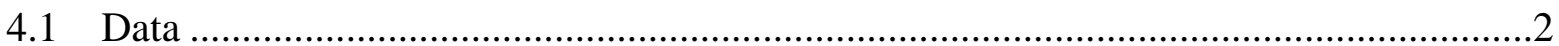

4.2 Getting Data Files Into the AMANDA Data Folder .................................................6

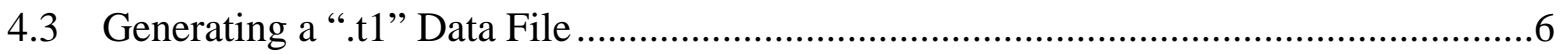

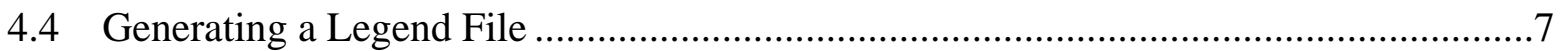

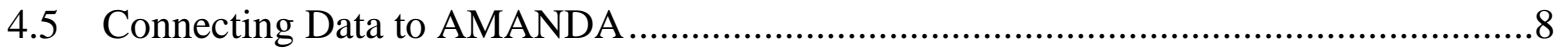

4.6 To Copy the File to the ORCA Data Folder...........................................................8

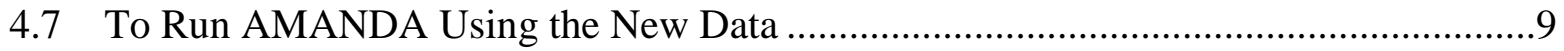

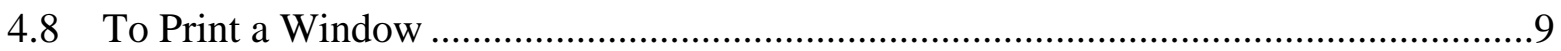

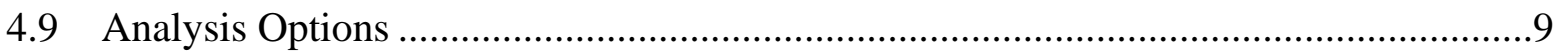

5. Recommended Improvements to Enhance AMANDA Model Capabilities Within the ORCA Modeling System

6. References $\quad 11$

$\begin{array}{ll}\text { Distribution List } & 12\end{array}$ 


\section{List of Figures}

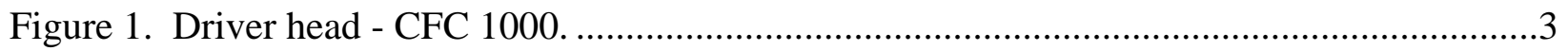

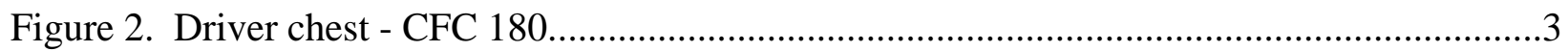

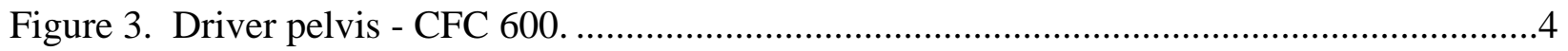

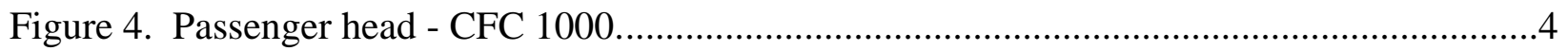

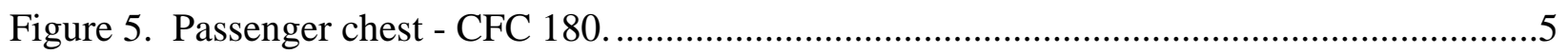

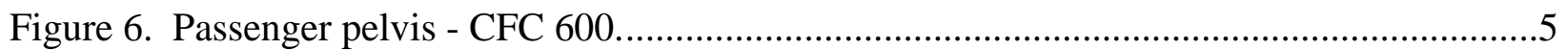

\section{List of Tables}

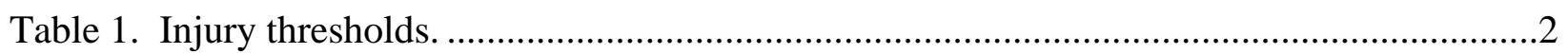

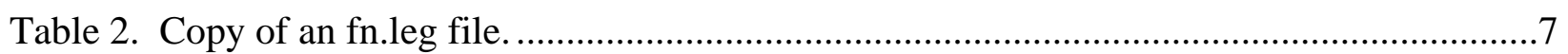




\section{Acknowledgments}

The author gratefully acknowledges Dr. Edward Davis (U.S. Army Research Laboratory, Aberdeen Proving Ground, MD) for the many valuable discussions and his technical contributions to this report. 
INTENTIONALLY LEFT BLANK. 


\section{Introduction}

This report describes the procedures for using the AMANDA model in acceleration response studies. AMANDA is an analysis software model that processes acceleration time-history data to determine injury thresholds. It is applied to personnel who are exposed to sudden acceleration, as described below. The model was developed by Dr. Nabih Alem (U.S. Army Aeromedical Research Laboratory, Fort Rucker, AL). In order to enhance clarification, an example from live-fire test data is included. It includes processing of acceleration time-history data for inputting the data into AMANDA $(1,2)$ and applying AMANDA, which predicts head, chest, and pelvis acceleration, in order to predict injury. It also includes recommended improvements to enhance AMANDA-model capabilities within the Operational Requirementbased Casualty Assessment (ORCA) $(3,4)$ modeling system. The ORCA modeling system is a computer software package that provides a comprehensive standardized casualty assessment methodology associated with weapon-induced injuries. Sets of acceleration time-history data from a live-fire test are included as an example in order to enhance the clarity of the described procedure.

\section{Analysis}

For purposes of describing the AMANDA modeling process, experimental data are applied as follows: A military vehicle was subjected to a mine explosion on the front right side. Instrumented driver and passenger manikins were used as sources of acceleration data. The instrumentation included three-axis accelerometers mounted on the head, chest, and pelvis of both the driver and passenger manikin.

The acceleration data were processed to make it compatible with the input/output (I/O) requirements of AMANDA. The processed data were then input and analyzed by AMANDA.

\section{Summary of Results}

In the experiment referred to previously, the setup and results are as follows. There were a total of six accelerometer positions:

1. Driver's head.

2. Driver's chest. 


\section{Driver's pelvis.}

4. Passenger's head.

5. Passenger's chest.

6. Passenger's pelvis.

Each of these consisted of three axes of accelerometer data in units of G's. The forward, lateral, and vertical axes are designated as $\mathrm{x}, \mathrm{y}$, and $\mathrm{z}$, respectively. There were no cases in which chest or pelvis injury thresholds were reached. The chest-injury thresholds (table 1) are the resultant of the three components, which implies the square root of the quadratic sum of the $\mathrm{x}, \mathrm{y}$, and $\mathrm{z}$ components of acceleration. The head injury criterion is not presented as a threshold, but as an index and a percentage of risk of brain injury.

Table 1. Injury thresholds.

\begin{tabular}{|c|c|c|c|c|}
\hline $\begin{array}{c}\text { Accelerometer } \\
\text { Location }\end{array}$ & Injury & $\begin{array}{c}\text { Injury } \\
\text { Thresholds }\end{array}$ & Driver & Passenger \\
\hline Head & HIC / \% risk & - & $3 / 0.3$ & $160 / 0.6$ \\
\hline Chest-forward & DRI-X / \% risk & \multirow{3}{*}{$\begin{array}{l}\text { (Resultant:) } \\
60 \text { G @ } 3 \text { ms } \\
40 \text { G @ } 7 \text { ms }\end{array}$} & $4.17 / 0.0$ & $6.53 / 0.0$ \\
\hline Chest-lateral & DRI-Y / \% risk & & $2.47 / 0.0$ & $10.27 / 0.0$ \\
\hline Chest-vertical & DRI-Z / \% risk & & $8.45 / 0.0$ & $14.71 / 0.0$ \\
\hline Pelvis-forward & DRI-X / \% risk & 40G@7 ms & $20.69 / 0.0$ & $14.46 / 0.0$ \\
\hline Pelvis-lateral & DRI-Y / \% risk & 23G@7 ms & $5.68 / 0.0$ & $7.49 / 0.0$ \\
\hline Pelvis-vertical & DRI-Z / \% risk & 23G@7 ms & $7.88 / 0.0$ & $13.79 / 0.0$ \\
\hline
\end{tabular}

To evaluate the signals, it was important that they be filtered per Society of Automotive Engineers (SAE) J211 (5) guidelines. Filtering reduces the peaks and allows valid comparison to the criteria established for each body part. The SAE J211 specifies channel filter class (CFC) for processing signals from crash dummies. The filters are as follows: CFC 1000 for the head, CFC 180 for the chest, and CFC 600 for the pelvis. These correspond to Butterworth filters of 1650, 300, and $1000 \mathrm{~Hz}$, respectively.

Figures 1-6 consist of the filtered acceleration vs. time graphs of the data sets for shot 10 . Each graph is labeled with the accelerator location and color coded with the accelerator orientation.

\section{Method of Analysis}

\subsection{Data}

The acceleration time-history data consist of two columns. The first column is time. The second is acceleration in G's $\left(1 G=32.2 \mathrm{ft} / \mathrm{s}^{2}\right)$. The input to the ORCA acceleration module requires that the data consist only of a column of up to 8000 lines of acceleration data. 


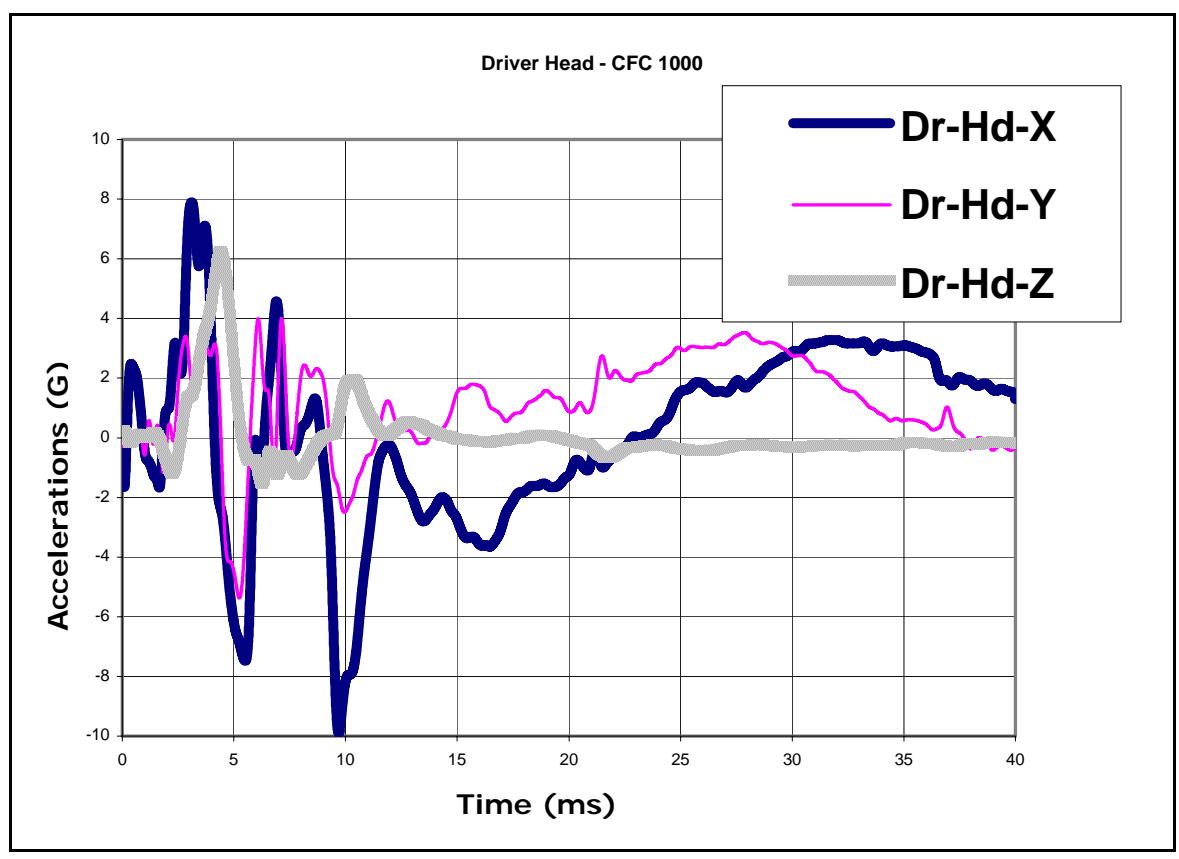

Figure 1. Driver head - CFC 1000.

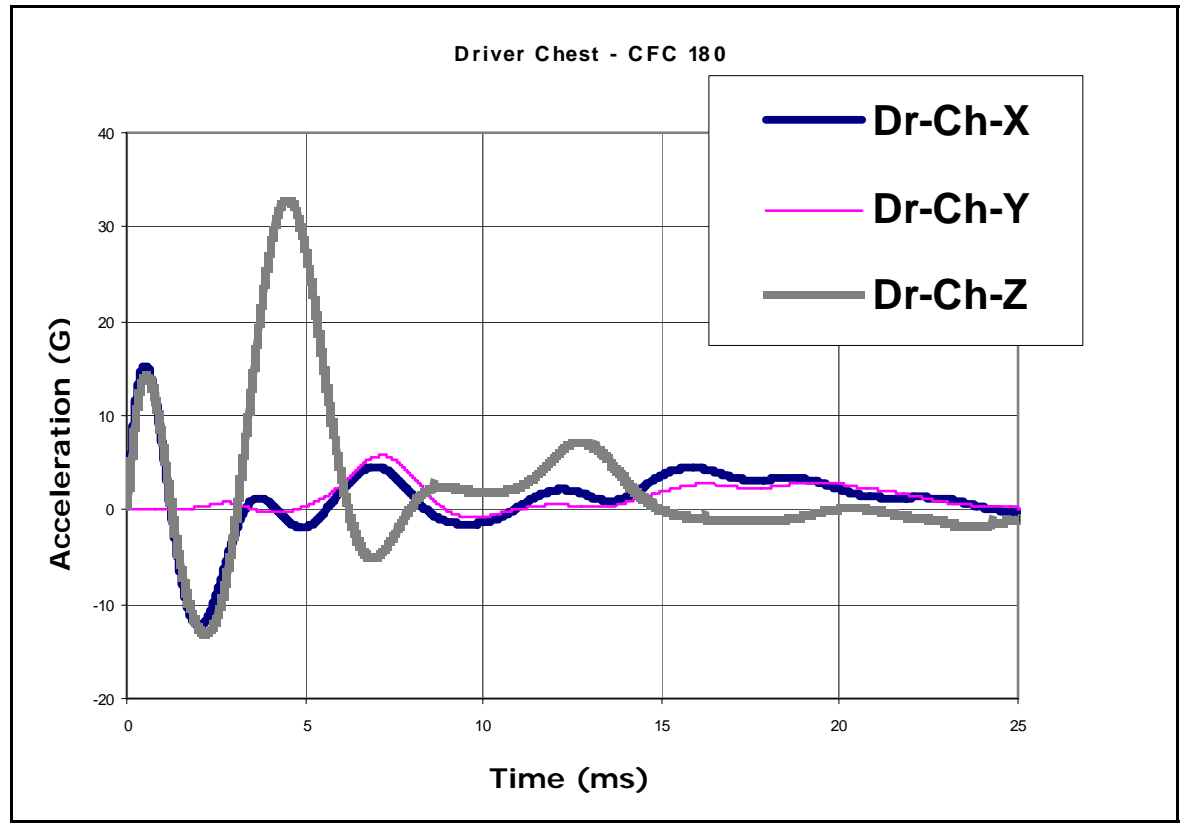

Figure 2. Driver chest - CFC 180. 




Figure 3. Driver pelvis - CFC 600.

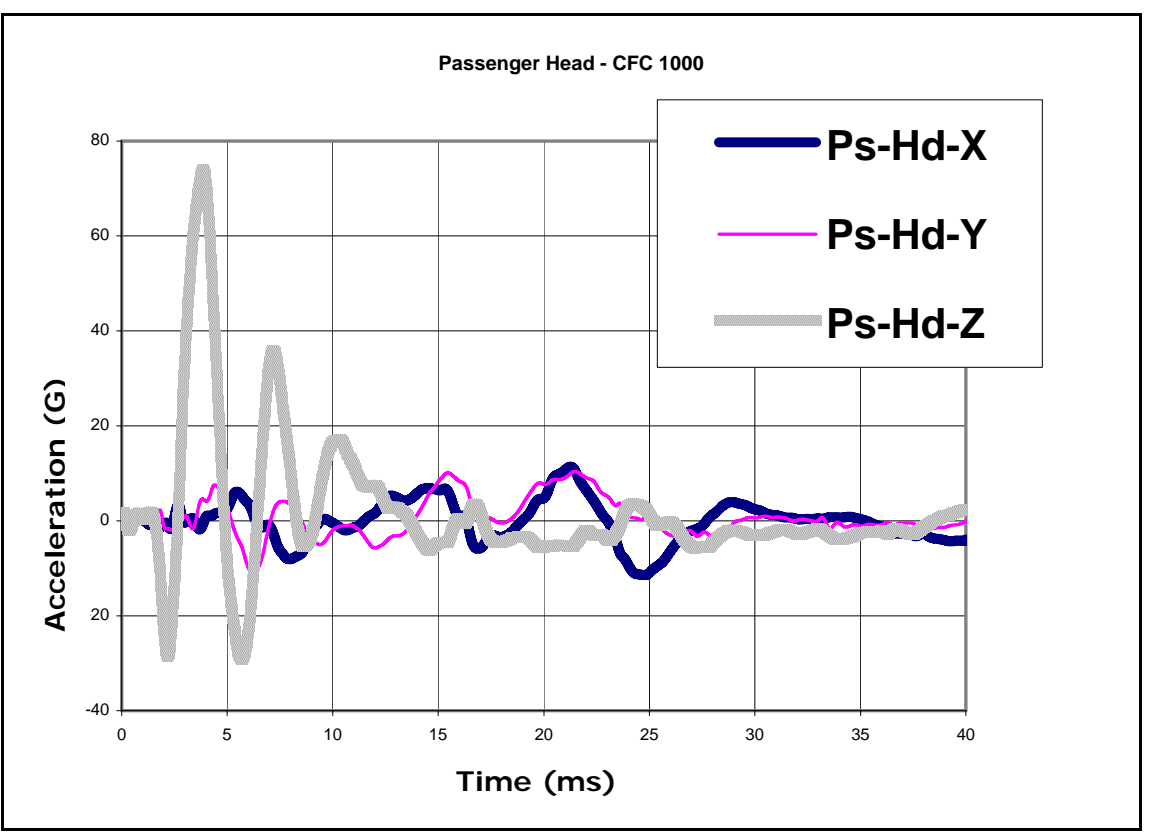

Figure 4. Passenger head - CFC 1000. 


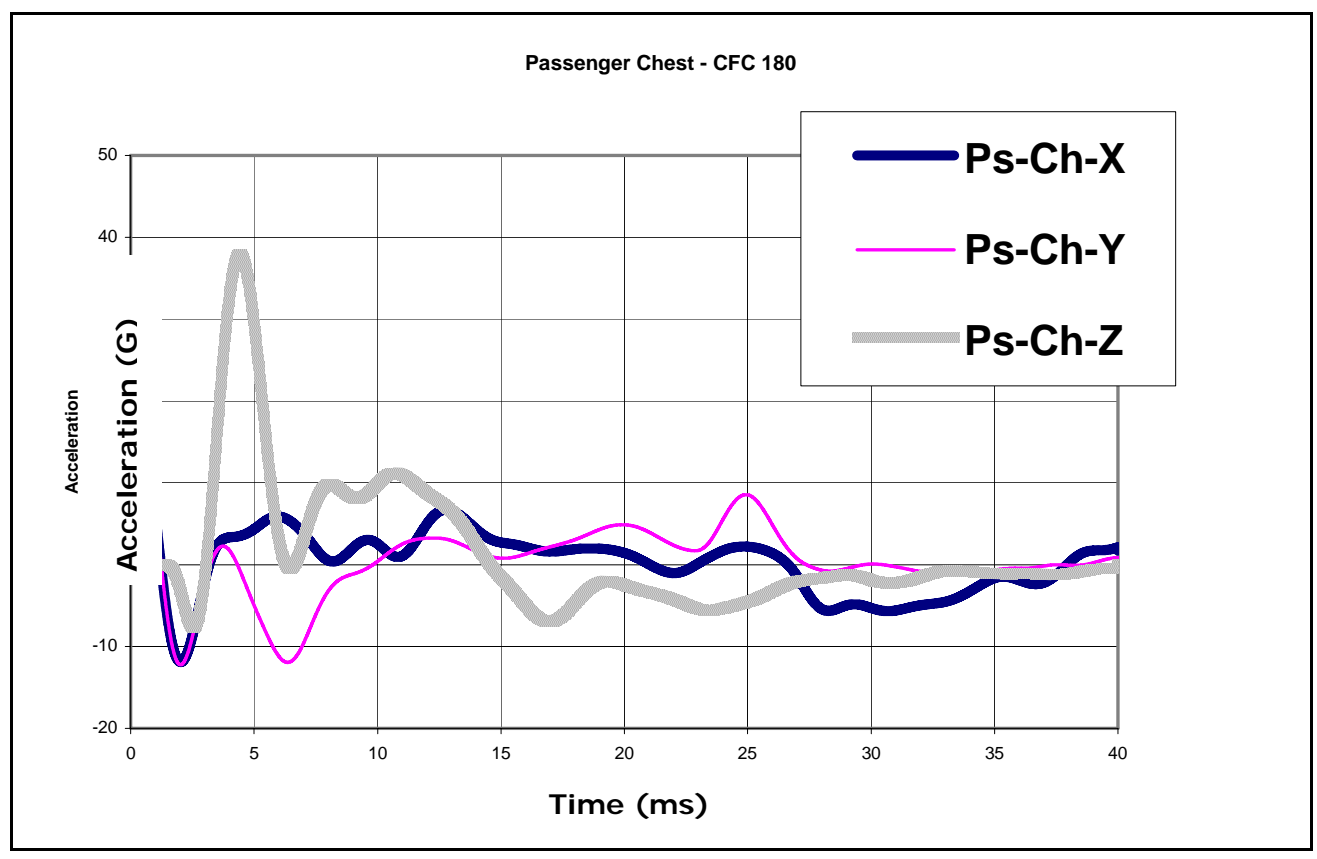

Figure 5. Passenger chest - CFC 180.

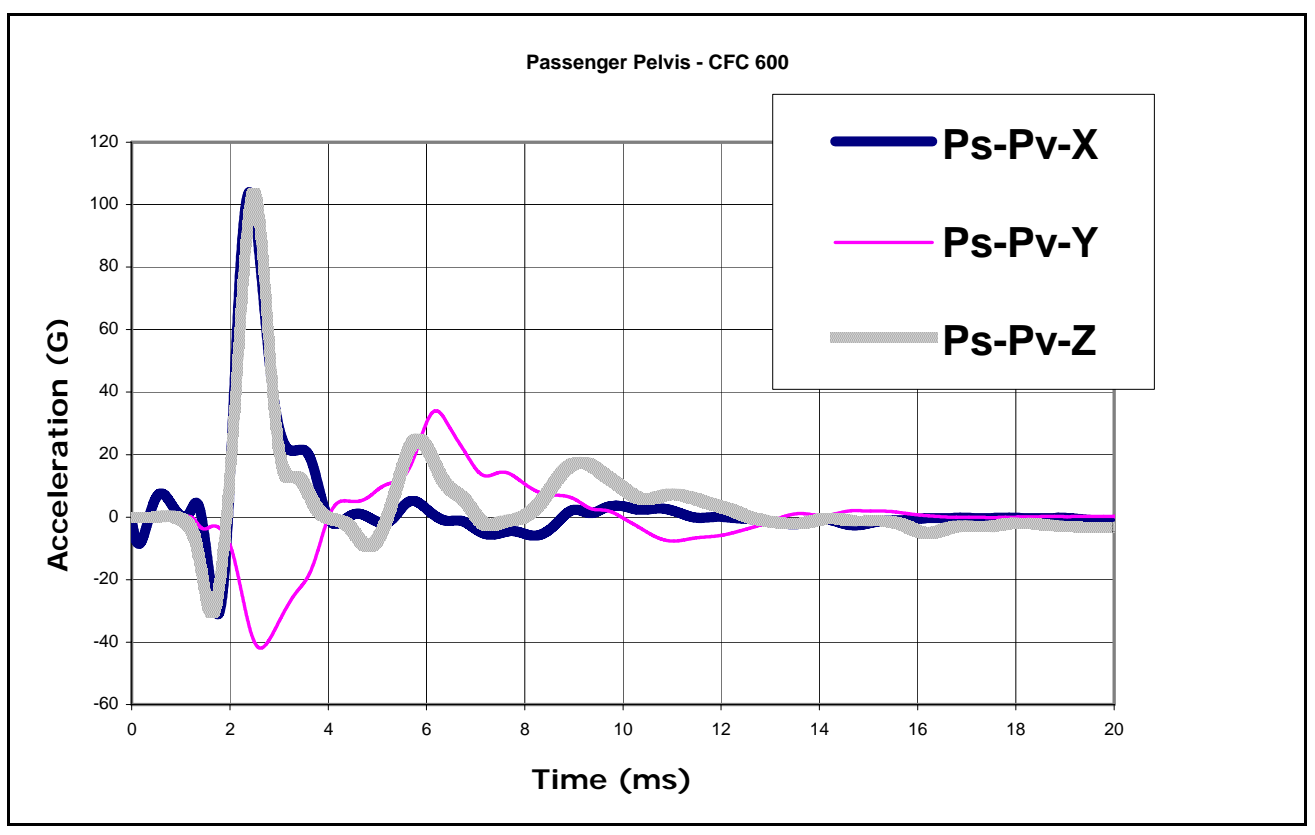

Figure 6. Passenger pelvis - CFC 600. 


\subsection{Getting Data Files Into the AMANDA Data Folder}

The filename includes the target and the accelerometer location and orientation. The data consist of two columns. The first is time in milliseconds. The second is the corresponding acceleration in units of G's. A G of acceleration is the acceleration on a massive object, at sea level, because of the Earth's gravitational field. The time intervals provide the user with the necessary information with which to calculate the sample frequency, in samples per second. The data processing consists of removing the time column and listing the acceleration column so that the first character space is either a "-” or the first character of a number. It also consists of selecting the "best" 8000 , or fewer, lines of acceleration data.

\subsection{Generating a “.t1” Data File}

1. The process begins with generating a "Notepad" file for each data file.

2. Left click "Edit.”

3. Left click "Select All."

4. $\quad$ Left click "Copy.”

5. Open an "Excel” file.

6. Left click with the arrow pointing at the first row of one of the columns.

7. Left click on "Edit” and left click on "Paste."

8. The sum of the two Notepad columns will be contained in the clicked-on column.

9. Left click on the first row of another column and insert a " 0. "

10. On the second row of that column, write the next time, from the time intervals in the data file.

11. Left click on the first row again.

12. Left click on the second row while pressing the shift key.

13. Point to the lower right corner of that "box" and press the left mouse button.

14. While holding down the left mouse button, slide downward on that column until you reach the 8000th row.

15. Return to the top by pointing to the scroll bar, pressing the left mouse button, and sliding it upward.

16. Click on the 1st row of another column.

17. Click on the equation bar. 
18. Write: = sum(a1-b1).

19. This is for the case when a1 is the data column and b1 is the time interval column.

20. Point to the lower right corner of the box, press the left mouse button, and slide down until the last data row.

21. The data have now been regenerated.

22. Click the left mouse button on the last data entry.

23. Return to the top, hold down the shift key, and click the left mouse button on the first row of the restored data column.

24. The entire column has been selected.

25. Left click on Edit and then left click on Copy.

26. Open a Notepad file.

27. Left click on Edit and then left click on Paste.

28. Left click on File; left click on "Save as."

29. Select a folder.

30. Write a file name: “file-name.t1.”

31. A “.t1” file for AMANDA analysis has now been generated.

\subsection{Generating a Legend File}

A software file called "COMPRESS" is used to connect data files to AMANDA. The input to COMPRESS is a legend file: "file-name.leg." This file has a required structure. There are five header lines followed by a blank line. Each line that follows is an fn.t1 data file name followed by a tab space and description. Table 2 is a copy of an fn.leg file.

Table 2. Copy of an fn.leg file.

\begin{tabular}{|c|c|}
\hline test0000.leg & 8-character filename \\
\hline First test case for software & 50-character description \\
\hline 8000,200000, & Max samples, sampling rate (Hz) \\
\hline 0,0, & Anti-alias filter (Hz, dB) \\
\hline 0,1, & Pre-0 samples, subsampling factor \\
\hline & \\
\hline ACC00001.T1 drivers head X (G) & Blank space, then 1st character \\
\hline ACC00002.T1 drivers head Y (G) & Blank space, then 1st character \\
\hline ACC00003.T1 drivers head Z (G) & Blank space, then 1st character \\
\hline
\end{tabular}


1. The first line consists of an 8-character id name, as shown.

2. The second line consists of a descriptive phrase. It can use up to 50 characters.

3. The third line consists of two integers, each followed by a comma. The first is the maximum number of lines of data which are to be included in the analysis. The second is the sampling rate in $\mathrm{Hz}$.

4. The fourth line consists of two integers, each followed by a comma. The first specifies the corner frequency in Hz. The second specifies the roll-off slope in dB/octave.

5. The fifth line consists of two integers, each followed by a comma. The first is the number of samples before $t=0$. The second is the subsampling factor: 8 means that one out of each eight samples will be analyzed.

6. The sixth line is blank.

7. The seventh line consists of the first file name. It can be up to 12 characters. The 1 st column must be left blank. The file name is followed by a tab. The 30-character sensor description, i.e., the location, the orientation, and the units of acceleration in parentheses of the accelerometer begin at column 17. The possible locations include the driver's or passenger's head, chest, or thorax.

8. Each succeeding line after the seventh is to be structured the same way. A line can be skipped between accelerometer sites: driver's head, driver's chest, etc.

\subsection{Connecting Data to AMANDA}

The "fn.t1" data files are called by the "fn.leg” file. A software file called COMPRESS, which compresses the data files, has a user entry line. Double click on COMPRESS, which is in the same folder as the .leg file and the .t1 files. The user enters the fn.leg file name. Compress processes the fn.t 1 files called by the fn.leg file and names the resulting file the same as the leg file name, but with the suffix .ACC.

\subsection{To Copy the File to the ORCA Data Folder}

1. Open the ORCA_program folder.

2. Double click on the contained ORCA folder.

3. Double click on the src folder.

4. Double click on the tcl folder.

5. Double click on the AMANDA folder.

6. Double click on the data folder.

7. Left click on the compressed fn.ACC file in the acceleration-data folder. 
8. Right click on the fn.ACC file and select "copy” from the pop-up menu.

9. Left click on the data folder window.

10. Right click in the window and select "Paste" from the pop-up menu.

11. Left click on the back option of the window-menu to return to the AMANDA window.

\subsection{To Run AMANDA Using the New Data}

1. Double click on run AMANDA - stand alone.

2. Double click on Browse (Data Set).

3. Select Data Set (Click); then “Okay.”

4. Select Files from Data Set: triax ...browse.

5. Analysis select options ....

6. Okay.

\subsection{To Print a Window}

1. Click the window.

2. Ctl-Alt-PrintScreen.

3. Paint: .

4. Paste: .

5. File/Print.

\subsection{Analysis Options}

1. Head: HIC (head injury criterion).

2. Chest: Table: chest resultant acceleration.

3.60G@3 ms or40G @7 ms.

4. Pelvis: DRI (Dynamic Response Index). 


\section{Recommended Improvements to Enhance AMANDA Model Capabilities Within the ORCA Modeling System}

AMANDA is presently incorporated in the ORCA modeling system. However, the AMANDA output only consists of predicted injury index levels. These indices, while they may be useful and applicable to injury modeling, presently need to be compared to injury threshold levels found in outside documents, in order to determine if there is predicted injury. Rather, it would be preferable to determine injury levels automatically by applying the injury threshold algorithms within ORCA/AMANDA software. Additionally, AMANDA-predicted injury levels need to be mapped into ORCA elemental capability vectors in order to predict incapacitation in a manner, which is consistent with ORCA predicted outputs for kinetic energy insults.

Extending AMANDA and improving its integration with ORCA can be done independently as two parts of the same ORCA improvement program. Both require algorithms and software development.

It is obvious from the present procedure of applying AMANDA, to determine predicted levels of injury, that it is complex and time consuming. The improvements to AMANDA and its improved integration with ORCA consists of the following steps:

1. The automation of processing acceleration data sets and inputting them into AMANDA.

2. Development of algorithms to apply the output of an AMANDA analysis to predicting injury levels.

3. Connecting the predicted injury levels outputs to ORCA in order to apply the ORCA incapacitation methodologies to them. The result will be predicted incapacitation for a given acceleration insult on a soldier with a specified mission. 


\section{References}

1. Alem, N. M. USAARL AMANDA Software Computer Code; U.S. Army Aeromedical Research Laboratory: Fort Rucker, AL, 1997.

2. Alem, N. M. Mine Blast Acceleration Injury Assessment: Methods, Criteria, and Software; USA ARL-97-28; U.S. Army Aeromedical Research Laboratory: Fort Rucker, AL, July 1997.

3. Neades, D. N.; Davis, E. G. A New Approach to the Simulation of Battlefield Injuries and Their Effect on the Performance of Military Trades. Proceedings of the $20^{\text {th }}$ International Symposium on Ballistics; Orlando, FL, September 2002.

4. Kaltenback, E.; Kilion, E.; Partch, J.; Streit, B. Operational Requirements-based Casualty Assessment (ORCA) User's Manual; ARA Project No. 0573; 2001.

5. Society of Automotive Engineers (SAE). Instrumentation for Impact Tests-Part IElectronic Instrumentation. SAE J211; Warrendale, PA, March 1995. 
NO. OF

COPIES ORGANIZATION

1 DEFENSE TECHNICAL

(PDF INFORMATION CTR

ONLY) DTIC OCA

8725 JOHN J KINGMAN RD

STE 0944

FT BELVOIR VA 22060-6218

1 US ARMY RSRCH DEV \& ENGRG CMD

SYSTEMS OF SYSTEMS

INTEGRATION

AMSRD SS T

6000 6TH ST STE 100

FORT BELVOIR VA 22060-5608

1 INST FOR ADVNCD TCHNLGY

THE UNIV OF TEXAS

AT AUSTIN

3925 W BRAKER LN STE 400

AUSTIN TX 78759-5316

1 US MILITARY ACADEMY

MATH SCI CTR EXCELLENCE

MADN MATH

THAYER HALL

WEST POINT NY 10996-1786

1 DIRECTOR

US ARMY RESEARCH LAB

IMNE AD IM DR

2800 POWDER MILL RD

ADELPHI MD 20783-1197

3 DIRECTOR

US ARMY RESEARCH LAB

AMSRD ARL CI OK TL

2800 POWDER MILL RD

ADELPHI MD 20783-1197

3 DIRECTOR

US ARMY RESEARCH LAB

AMSRD ARL CS IS T

2800 POWDER MILL RD

ADELPHI MD 20783-1197
NO. OF

COPIES ORGANIZATION

$\underline{\text { ABERDEEN PROVING GROUND }}$

1 DIR USARL

AMSRD ARL CI OK TP (BLDG 4600) 
NO. OF

COPIES ORGANIZATION

1 OASD C3I

J BUCHHEISTER

RM 3D174

6000 DEFENSE PENTAGON

WASHINGTON DC 20301-6000

1 OUSD(AT)/S\&T AIR WARFARE

R MUTZELBURG

RM 3E139

3090 DEFENSE PENTAGON

WASHINGTON DC 20301-3090

1 OUSD(AT)/S\&T LAND WARFARE

A VIILU

RM 3B1060

3090 DEFENSE PENTAGON

WASHINGTON DC 20310-3090

1 UNDER SECY OF THE ARMY

DUSA OR

RM 2E660

102 ARMY PENTAGON

WASHINGTON DC 20310-0102

1 ASST SECY ARMY

ACQSTN LOGISTICS \& TECH

SAAL ZP RM 2E661

103 ARMY PENTAGON

WASHINGTON DC 20310-0103

1 ASST SECY ARMY

ACQSTN LOGISTICS \& TECH SAAL ZS RM 3E448

103 ARMY PENTAGON

WASHINGTON DC 20310-0103

1 DIRECTOR FORCE DEV

DAPR FDZ

RM 3A522

460 ARMY PENTAGON

WASHINGTON DC 20310-0460

1 US ARMY TRADOC ANL CTR

ATRC W

A KEINTZ

WSMR NM 88002-5502

1 USARL

AMSRD ARL SL EA

R FLORES

WSMR NM 88002-5513
NO. OF

COPIES ORGANIZATION

1 USARL

AMSRD ARL SL EI

J NOWAK

FT MONMOUTH NJ 07703-5601

$\underline{\text { ABERDEEN PROVING GROUND }}$

1 US ARMY DEV TEST COM

CSTE DTC TT T

APG MD 21005-5055

1 US ARMY EVALUATION CTR

CSTE AEC SVE

R BOWEN

4120 SUSQUEHANNA AVE

APG MD 21005-3013

1 US ARMY EVALUATION CTR

CSTE AEC SVE S

R POLIMADEI

4120 SUSQUEHANNA AVE

APG MD 21005-3013

1 US ARMY EVALUATION CTR

CSTE AEC SV L

R LAUGHMAN

4120 SUSQUEHANNA AVE

APG MD 21005-3013

14 DIR USARL

AMSRD ARL SL

J BEILFUSS

P DEITZ

AMSRD ARL SL B

J FRANZ

M PERRY

P TANENBAUM

AMSRD ARL SL BB

D BELY

D FARENWALD

$S$ JUARASCIO

M RITONDO

AMSRD ARL SL BD

R GROTE

AMSRD ARL SL BE

L ROACH

AMSRD ARL SL E

M STARKS

AMSRD ARL SL EC

J FEENEY

E PANUSKA 
INTENTIONALLY LEFT BLANK. 